\title{
Glucose Availability Modulates the Timing of the Luteinizing Hormone Surge in the Ewe
}

\author{
Christopher L. Medina* $\uparrow^{1}$, Shoji Nagatani*, Tiffany A. Darling*, David C. Bucholtz*§, Hiroko Tsukamura**, \\ Kei-ichiro Maeda** and Douglas L. Foster* $\$$ \\ *Reproductive Sciences Program, †Unit for Laboratory Animal Medicine, and Departments of §Physiology, $\llbracket$ Biology, †Obstetrics and \\ Gynecology, University of Michigan, Ann Arbor, USA. \\ **Laboratory of Animal Reproduction, Nagoya University, Nagoya 464-01 Japan.
}

Key words: glucose availability, LH-surge, hypoglycemia.

\begin{abstract}
To determine if glucose availability modulates the timing of the positive feedback action of oestrogen on gonadotropin secretion, we monitored the estradiol-induced luteinizing hormone (LH) surge in sheep ( $n=5 /$ group) made transiently hypoglycemic by insulin. Experiment 1 determined an effective insulin treatment, one which would depress tonic LH secretion. Two injections of insulin (5 $\mathrm{IU} / \mathrm{kg}$ iv) $4 \mathrm{~h}$ apart were found to induce extended hypoglycemia (10-13 h) and to decrease the LH pulse frequency for $8 \mathrm{~h}(5.0 \pm 0.32$ pulses $/ 4 \mathrm{~h}$ before versus $2.5 \pm 0.34$ pulses $/ 4 \mathrm{~h}$ after insulin; $\mathrm{P}<0.05$; mean $\pm \mathrm{SEM}$ ). Using this same paradigm, experiment 2 determined the influence of the transient hypoglycemia on the LH surge mechanism. In control sheep, estradiol (subcutaneous implants at hour 0 ) evoked an LH surge with a latency period of $12.4 \pm 0.5 \mathrm{~h}$. When insulin was administered either before (hours -4 and 0 ) or after the estradiol stimulus (hours 4 and 8 , or 12 and 16 ), the onset of the LH surge was delayed to $29.0 \pm 2.4 \mathrm{~h}$ (average of all three time groups, $\mathrm{P}<0.05$ ). Infusion of glucose from hours $12-30$, along with insulin, prevented hypoglycemia and restored the normal timing of the oestrogen-induced LH surge to that of controls $(15.4 \pm 0.93 \mathrm{~h}$, $\mathrm{P}>0.05)$. These findings suggest that not only is the tonic mode of $\mathrm{LH}$ secretion sensitive to metabolic fuel availability, but the surge mode of LH secretion is as well.
\end{abstract}

Adequate nutrition is essential for the onset and maintenance of reproductive activity $(1,2)$. When dietary energy is limited, tonic luteinizing hormone ( $\mathrm{LH})$ secretion is impaired in the sheep $(3,4)$, rat $(5)$ and monkey $(6,7)$. Previous studies have determined that LH pulse frequency is suppressed under a reduced glucose availability by insulininduced hypoglycemia in the sheep (8), rat (9) and monkey (10), or by pharmacological blockade of glucose metabolism with 2-deoxyglucose (2DG) in the sheep (11) and rat $(12,13)$.

Most work has focused on the effect of glucose availability on pulsatile LH secretion, and there has been relatively less attention paid to the LH surge mechanism in this regard. In those limited studies of the surge system, there is little consensus as to the effects of energy deficiency. In the rat
(14), glucoprivation induced by $2 \mathrm{DG}$ blocked the progesterone-induced LH surge; however, in the hamster (15), $48 \mathrm{~h}$ of fasting was unable to prevent the LH surge. In the developing sheep, in which the growth rate is restricted by reduced nutrition, the amplitude of the oestrogen-induced LH surge was found to be reduced in the presence of chronic estradiol treatment, but not in its absence (16). In the current study of the young adult female sheep, our approach was to produce short-term periods of hypoglycemia before or after the initiation of a surge induced by estradiol treatment to assess which time period(s), if any, are sensitive to metabolic fuel availability. The LH surge mechanism in sheep is exclusively dependent on increased concentrations of circulating oestrogen (17) in contrast to rodents in which oestrogen positive feedback is modulated

\footnotetext{
${ }^{1}$ Present address: Abbott Laboratories, Pharmaceutical Products Division, Building AP13 A, 100 Abbott Park Road, Abbott Park, IL 60064-3500, USA. A preliminary report of this work has been presented at the Twenty-Seventh Annual Meeting of the Society for Neuroscience, New Orleans, USA, October 1997 (Abstract no. 42.12).

Correspondence to: Douglas L. Foster, Room 1101, 300 North Ingalls Building, University of Michigan, Ann Arbor, MI 48109-0404, USA (e-mail: dlfoster@umich.edu).
} 
786 Glucose availability and luteinizing hormone surge

by circadian rhythm (18). This circadian-independent character facilitates the study of which time periods of oestrogen positive feedback, could be sensitive to glucose availability. In the present investigation, we examine which of the two stages of the LH surge phase is sensitive to a reduction of glucose availability: (1) the early follicular phase which includes processing of the estradiol signal, or (2) the late follicular phase during which the GnRH neurones are activated to secrete massive amounts of the neuropeptide into the pituitary portal circulation (19). We determined if the same acute inhibition in glucose availability which disrupts pulsatile LH secretion also modifies the timing of the LH surge. As a model, we used the oestrogen-induced LH surge in ovariectomized (OVX) sheep; transient hypoglycemia was produced by administration of insulin, because the depth and duration of hypoglycemia is easily assessed by monitoring circulating glucose levels.

\section{Results}

\section{Tonic luteinizing hormone secretion}

Insulin treatment suppressed circulating glucose in all animals (Fig. 1). Circulating glucose concentrations decreased abruptly after the initial insulin injection and remained suppressed throughout the remainder of the study $(\mathrm{P}<0.05$, Fig. 2).

The influence of transient hypoglycemia on the pattern of pulsatile LH secretion is presented in Fig. 1; the mean results are shown in Fig. 2. Luteinizing hormone pulse frequency was high during the control period. This was significantly $(\mathrm{P}<0.05)$ decreased after the initial insulin treatment, but did not decline further after the second treatment. Mean LH concentrations during the control period significantly $(\mathrm{P}<0.05)$ decreased after the first insulin treatment, and decreased further after the second insulin treatment $(\mathrm{P}<0.05)$.

\section{Luteinizing hormone surge system}

Insulin treatment produced approximately $12 \mathrm{~h}$ of hypoglycemia (Fig. 3, shaded areas: time when glucose $<50 \%$ pretreatment period). Parameters of the LH surge is presented in Fig. 4 for each of the treatments. In the control group, the LH surge began $12.4 \pm 0.5 \mathrm{~h}$ after insertion of the estradiol implants, peaked at $17.2 \pm 0.6 \mathrm{~h}$, had a duration of $19.6 \pm 3.1 \mathrm{~h}$, and an amplitude of $251.8 \pm 47.7 \mathrm{ng} / \mathrm{mL}$ of $\mathrm{LH}$. Transient hypoglycemia delayed, but did not prevent, the LH surge. With the exception of one treatment in one female (no. 567, insulin at hours 12 and 16; Fig. 3), the LH surge did not occur until circulating glucose levels returned to the normal range. Specifically, hypoglycemia approximately doubled the latent period compared to the control when insulin was administered at hours -4 and 0 , hours 4 and 8, hours 12 and 16 . The interval from the onset of the surge to its peak was similar in all groups. When administered before and at the time estradiol treatment, insulin did not reduce the duration or amplitude of the LH surge. The amplitude of the LH surge did decrease, however, when insulin was administered after the initiation of the estradiol

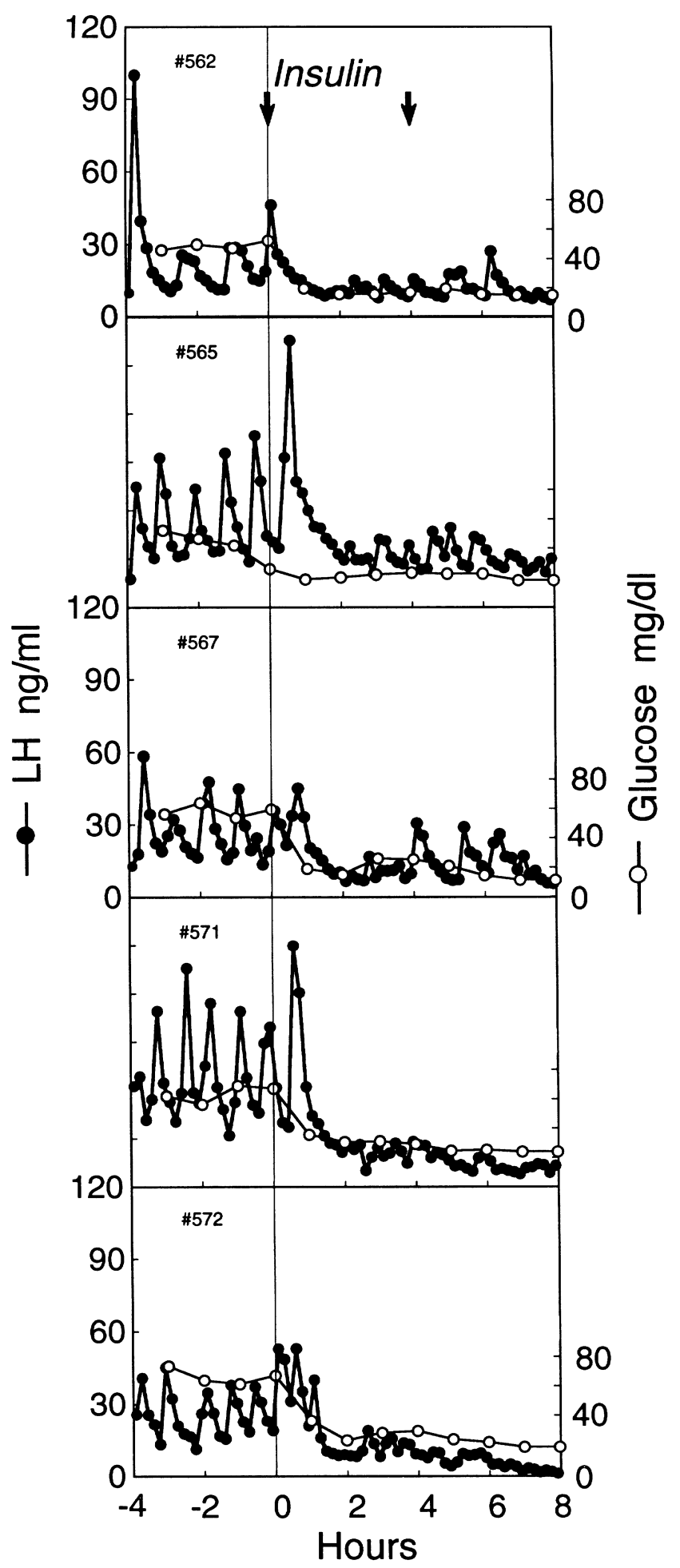

FIG. 1. Patterns of circulating luteinizing hormone and glucose in individual ovariectomized yearling ewes receiving an insulin injection( 5 $\mathrm{IU} / \mathrm{kg}$, i.v.; arrows) at hours 0 and 4.

treatment (hours 4 and 8 or hours 12 and 16, $\mathrm{P}<0.05$, Fig. 4).

Glucose replacement (during insulin treatment at hours 12 and 16) ameliorated the hypoglycemic effects of insulin 


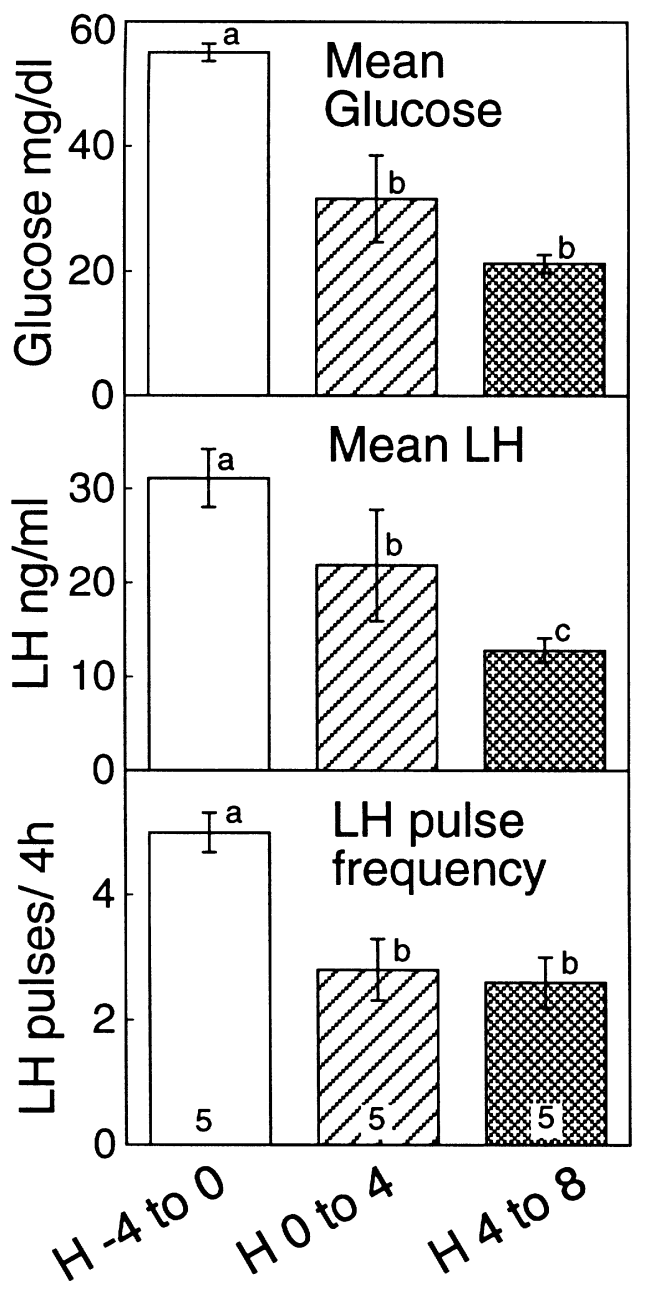

FIG. 2. Glucose levels (upper panel), mean luteinizing hormone (LH) concentrations (middle panel) and the number of LH pulses (lower panel) $0-4 \mathrm{~h}$ before, and $0-4 \mathrm{~h}$ and $4-8 \mathrm{~h}$ after insulin treatment (5 $\mathrm{IU} / \mathrm{kg}$, i.v.) at hours 0 and 4 . Values are given as mean \pm SEM. The significant difference $(\mathrm{P}<0.05)$ is indicated by exclusively different letters.

treatment on the timing of the surge and reinstated the normal latency time to its onset $(\mathrm{P}>0.05)$. The amplitude of the LH surge was not restored by exogenous glucose $(\mathrm{P}<0.05$, Fig. 4).

\section{Behaviour}

No overt behavioural changes occurred after the first insulin injection. However, after the second insulin injection, some animals in some occasions in both experiments showed mild muscle fasciculations and transient bouts of disorientation.

\section{Discussion}

The results of the present study clearly reveal that the preovulatory surge of $\mathrm{LH}$ is sensitive to metabolic fuel availability when a depth and duration of transient hypoglycemia is experienced which is capable of acutely inhibiting pulsatile LH secretion. In the OVX rat (14), suppression of progesterone-induced LH surge by energy deprivation could be explained by altering the circadian rhythm underlying the surge mechanism; a reduction of energy interferes with a variety of circadian rhythm in rats $(20,21)$. This hypothesis cannot account for the finding in this study of the sheep. At the outset, the period of the hypoglycemic delay in the LH surge was not $24 \mathrm{~h}$, but rather ranged between 14 and $19 \mathrm{~h}$. Moreover, the surge mechanism of the sheep is not sensitive to the circadian input as evidenced by the finding that administration of estradiol during the day or night results in an LH surge after a similar latent period, rather than occurring at a fixed time of day $(22,23)$. Similarly, the first $\mathrm{LH}$ surge at puberty in the sheep does not occur at a fixed time of day (24).

Interestingly, one might argue that insulin-induced hypoglycemia could delay the oestrogen-induced LH surge because of its effect on the tonic secretion of LH. It has been reported that a high frequency of $\mathrm{GnRH}$ and $\mathrm{LH}$ pulses precede the LH surge $(25,26)$ when circulating oestrogen levels increase in the ewe. The present results as well as previous study of Clarke et al. (8) indicate that pulsatile LH secretion is suppressed by hypoglycemia. However, it is difficult to know the border between tonic and surge modes of $\mathrm{GnRH}$ secretion, because it is not clear if the robust GnRH pulses found before and during the initiation of the GnRH surge are derived solely from GnRH pulse (tonic) generator. Because the frequency of multiple unit activity (MUA), considered to represent the activity of the GnRH pulse generator, decreases before and during oestrogen-induced LH surge (goat (27), monkey (28) and rat (29)), it has been proposed that there is an independent GnRH surge generator which could be driven by higher levels of oestrogen. Thus, in the present study, we cannot be assured that the transient hypoglycemia produced immediately before the ascending limb of the GnRH surge interfered with only the surge mechanism. However, insulin-induced hypoglycemia produced during the predicted onset of the surge (insulin at hours 12 and $16 \mathrm{~h}$ ) should have interfered with the surge without affecting the preceding GnRH pulses.

The time when hypoglycemia was produced relative to the oestrogen stimulus is an important factor affecting the shape of the LH surge. When hypoglycemia was began shortly before and at the time of the estradiol increment (insulin at hours -4 and 0 ), the surge was uniformly delayed, but amplitude was not affected. When the same depth and duration (10-13 h) of hypoglycemia was begun at later times during the 12-hour latent period, the LH surge was also delayed, but to a more variable extent in individuals. Thus, sensitivity to hypoglycemia seems to exist throughout the entire 12-hour latent period and beyond. Moreover, administration of glucose during treatment with insulin at hours 12 and 16 prevented the delay in the initiation of the LH surge. Therefore, the delay in the LH surge in the present study is likely to be a result of the glucoprivic effects of insulin treatment, rather than a direct effect of insulin per se.

Even though glucose infusion prevented the effects of insulin treatment on the timing of the oestrogen-induced $\mathrm{LH}$ surge, the present results do not exclude the possible roles of insulin determining the amplitude of the LH surge. The attenuated amplitude of the LH surge after insulin was not restored by glucose replacement. Similarly, it is reported that 


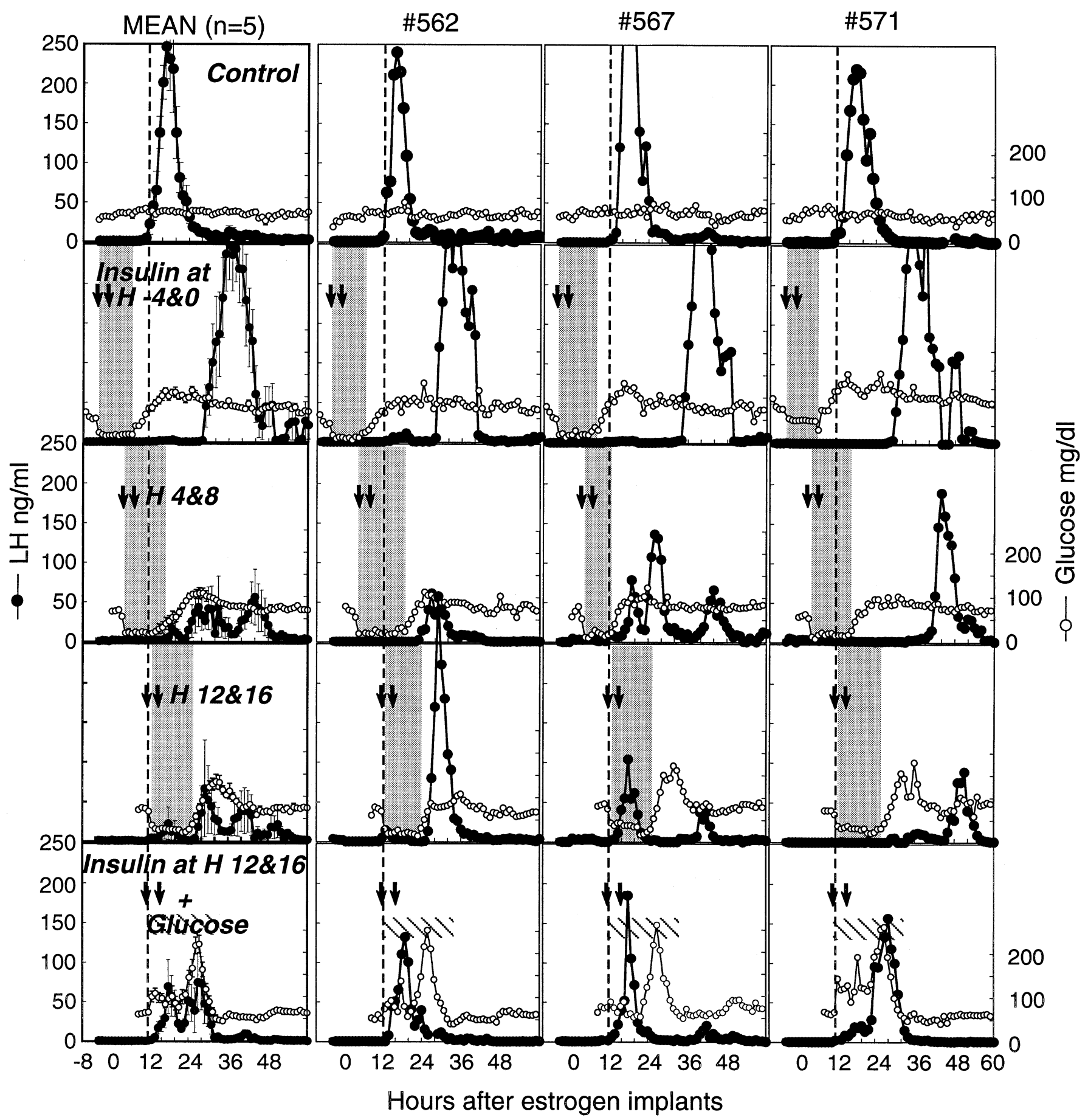

Fig. 3. Mean ( $n=5$; left panels) changes in circulating luteinizing hormone (LH) and glucose in three representative oestrogen-treated (hour 0) yearling ewes. Top row panels represent controls. In experimental groups (bottom panels), insulin was injected (5 IU/kg, i.v.; arrows) at hours -4 and 0 (second row panels), 0 and 4 (third row panels), 12 and 16 (fourth row panels). Bottom row panel depict glucose-replacement (hatched period; hours 12 through 30) simultaneously with insulin treatment (hours 12 and 16). The dotted line in each panel shows the averaged onset time of LH surge in control group. Shaded areas depict when circulating glucose concentrations were below the half those during the pre-insulin treatment period.

the glucose clamp during insulin-induced hypoglycemia fails to restore mean levels of plasma $\mathrm{LH}$ in the presence of oestrogen, but not its absence in castrated male sheep (30). There might be a direct suppressive action of insulin on LH secretion in the presence of oestrogen, although the detail mechanisms is not well known. Insulin can also alter energy metabolism through mechanisms other than by inducing hypoglycemia. For example, high doses of insulin inhibit lipolysis and fatty acid mobilization by adipose tissue (31). Thus animals treated with insulin in the present study may 


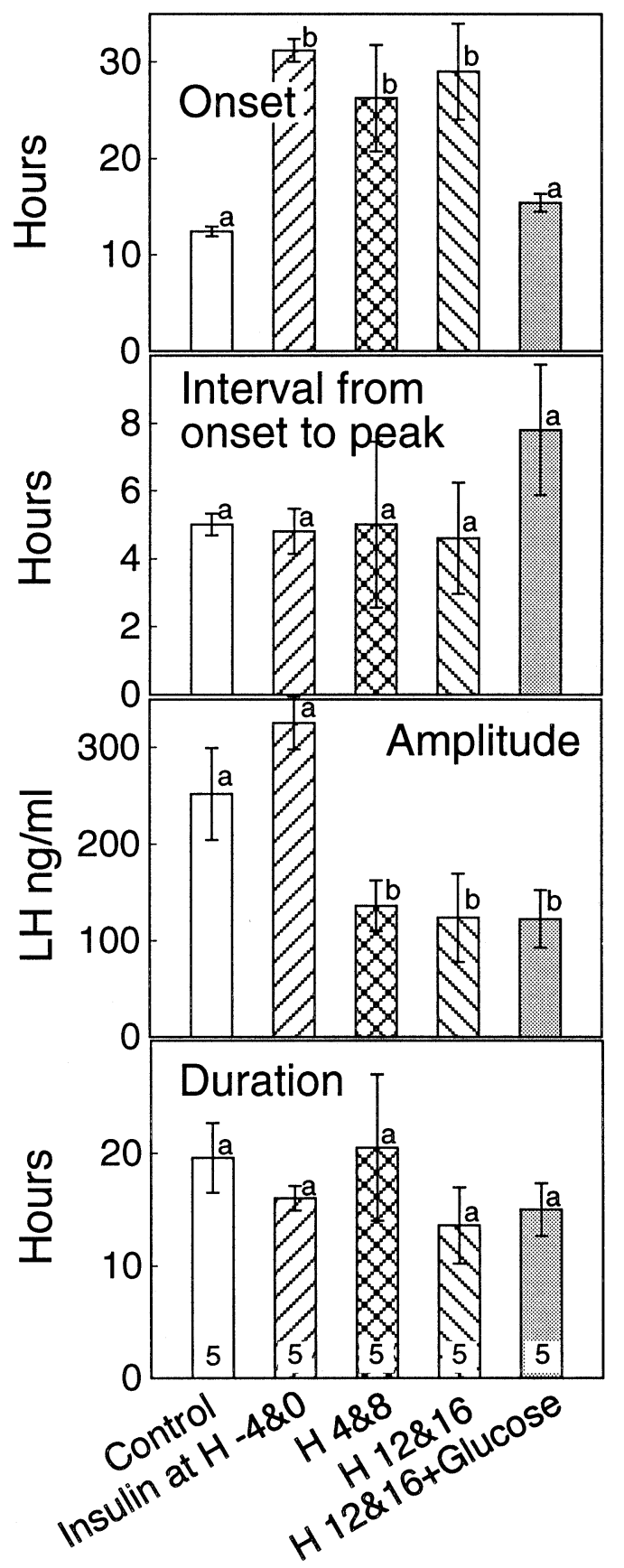

FIG. 4. Time of onset, peak time, duration, amplitude of peak luteinizing hormone $(\mathrm{LH})$, and time interval to peak $\mathrm{LH}$ concentration $(n=5$, mean \pm SEM $)$ in control, insulin alone $(5 \mathrm{IU} / \mathrm{kg}$, hours -4 and 0,4 and 8 , or 12 and 15) or insulin (hour 12 and 16) plus glucose treatment (hours 12-30) groups. The significant difference $(\mathrm{P}<0.05)$ is indicated by exclusively different letters.

have been deprived of fatty acids as an energy source, in addition to the hypoglycemia. In this respect, the suppressive effect of $2 \mathrm{DG}$ on ovulatory cycles is greatly potentiated by inhibition of fatty acid utilization (32). Interestingly, there may be differential sensitivities of the timing and amplitude properties of the surge mechanism to the source of energy. This could explain why the amplitude of the surge was not affected despite its onset being delayed when hypoglycemia was experienced before and at the initiation of the estradiol stimulus (insulin at hours -4 and 0 ). Perhaps during this period, the surge generating mechanism is exclusively sensitive to glucose availability, but not to other types of energy.

The present study indicates that insulin-induced hypoglycemia interferes with two stages of the LH surge: (1) a preparatory phase which includes processing of the estradiol signal and (2) a releasing phase during which the GnRH neurones secrete massive amounts of the neuropeptide into the pituitary portal circulation. During the releasing phase, refractoriness of the pituitary during hypoglycemia could be possible. Hypoglycemia begun at the putative onset of the LH surge (insulin at hours 12 and 16) delayed the surge, and the LH surge started after hypoglycemia in all animals except one (no. 567 in Fig. 3). Thus, the pituitary may have reduced its sensitivity to the GnRH stimulus under hypoglycemia but then recovered it while the GnRH surge continued; in sheep the duration of $\mathrm{GnRH}$ surge is known to be much longer than that of LH surge (33). This explanation, however, should be tempered by the finding that pituitary sensitivity to exogenous $\mathrm{GnRH}$ challenge is maintained during glucoprivation induced by $2 \mathrm{DG}$ in sheep and the rat $(11,12)$.

Rather than pituitary insensitivity being responsible for the absence of the LH surge during the appropriate time, a more likely possibility is that the induction of the GnRH surge itself was delayed. Perhaps GnRH neurones which are important to generating the GnRH surge, wherever their location, are not activated by oestrogen during hypoglycemia. In the present study, $9 \mathrm{~h}$ of hypoglycemia after the initiation of the oestrogen treatment (insulin at hours -4 and 0 ) uniformly delayed the onset of the LH surge for $18 \mathrm{~h}$. In sheep, increasing doses of oestrogen advance the onset of LH surge (17) and, perhaps, the occupancy of brain oestrogen receptors above a threshold is the signal to trigger the GnRH surge. One mechanism by hypoglycemia may prevent the LH surge is by reducing oestrogen receptor levels in the hypothalamic neurones which are involved in the GnRH surge. However, contrary to this hypothesis, Wade's group (15) has found in the Syrian hamster that $48 \mathrm{~h}$ of food deprivation increased responsiveness to the positive feedback effect of oestrogen by augmenting the oestrogen-receptor immunoreactive neurones in the medial preoptic area, which is considered as the primary positive feedback site of oestrogen in the rodents (34). In sheep, where the ventromedial nucleus of the hypothalamus is the primary action site of estradiol in inducing the GnRH surge (35), it is not known if food deprivation or hypoglycemia affects the number or function of oestrogen receptors in the nucleus.

Whether the likely activation of the stress axis by insulininduced hypoglycemia was the mechanism which delayed the LH surge in our study is not known. Stress is one of the most potent inhibitors of the $\mathrm{LH}$ surge in a large number of animals including sheep (36). Insulin-induced hypoglycemia is a potent stimulator of the hypothalamo-pituitary-adrenal axis in the rat (37), monkey (38) and sheep (39, 40). The effect of cortisol in inhibiting the LH surge remains inconclusive. A preliminary study in sheep has determined that a prolonged (5-day) infusion of cortisol can block or delay the preovulatory surge of LH (41). However, short-term (hours) 
treatment of the sheep with either cortisol or dexamethasone did not influence the estradiol-induced LH surge (42). On the other hand, the central action of CRH, AVP or opioid peptides, rather than cortisol, may be involved in the stressinduced suppression of the LH surge. Indeed, specific agonists of opioid peptides are reported to inhibit oestrogen-induced GnRH surge in sheep (43), but the role of CRH and AVP in the regulation of the surge mechanism in this species has not been examined yet.

It is impossible to know the extent of glucose utilization under each experimental condition or the sensitivity of the neural mechanisms responding to the glucose availability to regulate $\mathrm{GnRH}$ secretion in animals used in these experiments. The reduction of glucose availability in the present experiment must have been enough to suppress oestrogeninduced LH surge, judging from the observation that some animals in some occasions showed moderate or transient clinical signs typical of a prolonged hypoglycemia. Although we can not exclude the possibility that the LH surge was affected by a general hypoglycemia due to pharmacological doses of insulin used in this study, the present findings reveal that in addition to the mechanisms controlling tonic $\mathrm{LH}$ secretion, those governing the LH surge mechanism are also potentially sensitive to glucose availability.

\section{Materials and methods}

Animals

Post-pubertal, spring-born (April) yearling females $(50-60 \mathrm{~kg})$ of predominantly Suffolk breeding were studied between March and August at the Reproductive Sciences Program Sheep Research Facility at the University of Michigan, Ann Arbor, USA. The young adult females were maintained outdoors on fresh pasture and hay. The ovaries had been removed at 3 weeks of age via midline abdominal incision under general anaesthesia [atropine $(0.2 \mathrm{mg} / \mathrm{kg})$, xylazine $(0.1-0.2 \mathrm{mg} / \mathrm{kg})$, and ketamine $(10-20 \mathrm{mg} / \mathrm{kg})]$. The animals were maintained indoors and provided food ad libitum during the sampling period. All procedures were approved by University Committee on Use and Care of Animals in University of Michigan.

\section{Experimental design}

Experiment 1: Tonic luteinizing hormone secretion

To determine the effects of transient hypoglycemia on tonic LH secretion, jugular blood was collected from five ovariectomized sheep every 10 min over a 12-h period during which insulin was injected intravenously at hours 4 and 8 (5 IU $/ \mathrm{kg}$ regular insulin, Ely Lilly, Inc., Indianapolis, IN, USA). The protocol was a modification of the earlier study of Clarke et al. (8); we administered insulin twice rather than once to achieve a more sustained period of hypoglycemia.

Experiment 2: Oestrogen-induced luteinizing hormone surge

To determine the effects of hypoglycemia on the estradiol-induced LH surge, jugular blood was collected every hour beginning 4 or $8 \mathrm{~h}$ before and continuing for $60 \mathrm{~h}$ after a surge-inducing dose of estradiol (hour 0 ). Insulin was administered ( $5 \mathrm{IU} / \mathrm{kg}$, iv) at hours -4 and 0 , hours 4 and 8 , and hours 12 and 16 to induce periods (approximately $12 \mathrm{~h}$ ) of hypoglycemia before, during and after the normal time of onset of the LH surge. The experiment was conducted in five replicates of five animals per treatment such that each animal received each treatment and served as its own control. Treatments were not assigned in random order; we proceeded with the experiments one by one to explore the effects of hypoglycemia relative to the oestrogen treatment. In the final replicate, glucose was replaced by intravenous infusion throughout the period of hypoglycemia induced by insulin treatment at hours 12 and 16 . We chose a paradigm of insulin at hours 12 and 16 for glucose replacement study, because it was most effective to inhibit the oestrogeninduced LH surge among three treatments of insulin.

\section{Luteinizing hormone surge induction}

To achieve low, stable baseline levels of LH, a single Silastic implant containing estradiol was inserted 1 week before each surge-induction experiment. This steroid treatment produces serum estradiol levels of approximately $3-5 \mathrm{pg} / \mathrm{mL}$, sufficient to suppress LH during the non-breeding season $(44,45)$. To induce an LH surge, four additional estradiol implants were placed subcutaneously at hour 0 . Such treatment is known to provide a surge-inducing dose of estradiol (i.e. circulating estradiol concentrations of approximately $12 \mathrm{pg} / \mathrm{mL}$ ) (46). Each implant consisted of a $30-\mathrm{mm}$ packed column of crystalline estradiol 17- $\beta$ (Sigma Chemical Co., St. Louis, MO, USA) in Silastic tubing (o.d. $0.46 \mathrm{~cm}$, i.d. $0.34 \mathrm{~cm}$, Dow Corning, Midland, MI, USA) sealed by Silastic adhesive type A (Dow Corning). Before implantation, all estradiol capsules were preincubated in water for $18-20 \mathrm{~h}$ to prevent a peak in post-implantation steroid release (47). Immediately after each treatment, all five estradiol implants were removed. The next treatment (reinsertion of a single estradiol implant) was begun 3 weeks later.

\section{Glucose infusion}

In a pilot study with three sheep, the approximate dose and infusion rate of glucose to prevent hypoglycemia during insulin administration was determined (data not shown). For the glucose treatment used in the main experiment, each individual first received $50 \%$ glucose (Butler Co., Columbus, OH, USA) by an intravenous injection (jugular vein, $7 \mathrm{~mL}$ ) at hour 12 (immediately before insulin treatment). This was followed by an infusion of the $50 \%$ glucose $(30 \mathrm{~mL} / \mathrm{h}$ for $15 \mathrm{~h}$ ) by a peristaltic pump (Gilson Minipuls, Middleton, WI, USA) through prefitted jugular cannulae (Angiocath, Becton Dickinson, Mountain View, CA, USA). We prolonged the glucose infusion period by $3 \mathrm{~h}$ beyond the average period of hypoglycemia $(12 \mathrm{~h})$ to ensure that we had the maximal coverage with insulin. Additional glucose treatments ( $4 \mathrm{~mL} /$ treatment) were administered as an intravenous bolus when needed to maintain blood glucose at or above pre-insulin control levels for $4 \mathrm{~h}$, as determined from whole blood glucose measurements using a portable glucometer (Lifescan, Johnson \& Johnson, Milpitas, CA, USA).

\section{Blood sample collection}

After collection, blood samples $(2.0 \mathrm{~mL})$ for $\mathrm{LH}$ and glucose determination were dispensed into tubes containing $20 \mathrm{IU}$ heparin and $5 \mathrm{mg}$ sodium fluoride to prevent glucose metabolism by red blood cells. Following centrifugation, plasma was harvested and stored frozen at $-20{ }^{\circ} \mathrm{C}$ for later analysis.

\section{Hormone assays}

Luteinizing hormone was measured in duplicate $25-200 \mu \mathrm{L}$ aliquots of plasma using a modified $(48,49)$ RIA developed by Niswender et al. (50). Assay sensitivity, defined as $2 \times \mathrm{SD}$ from the buffer control, averaged $0.97 \pm 0.53 \mathrm{ng} / \mathrm{mL}(\mathrm{n}=10$ assays $)$ for $200 \mu \mathrm{L}$ plasma expressed relative to NIH-LH-S12. Intra-assay coefficient of variation (CV), determined from a serum pool which bound at $20 \%$, averaged $8.0 \%$, and interassay $\mathrm{CV}$ averaged $12.82 \%$. Glucose was measured in single $5 \mu \mathrm{L}$ aliquots of plasma using an Enzymatic Glucose ( Trinder) Kit (Sigma Chemical Co., St. Louis, MO, USA).

\section{Data analysis}

An onset time of LH surge was identified using the criterion established by Legan et al. (51), wherein a 'surge' is denoted by LH values which exceed $5 \mathrm{ng} / \mathrm{mL}$ for a minimum of $8 \mathrm{~h}$. The amplitude of the LH surge was determined by subtracting the average baseline value before estradiol treatment from the peak value of $\mathrm{LH}$ after estradiol supplementation. The interval to the peak of the LH surge was determined by subtracting the time of onset from the peak time. The end of the surge was defined as the first of three consecutive samples that decreased to the average baseline concentration of LH. If a second peak of LH occurred, a nadir point between the peaks was defined as the end of the original surge. The duration of the surge was determined by the difference between the time of surge onset and its end.

Mean glucose levels in each group were calculated for each sampling time. Control values were calculated by averaging the values of the first four sampling points in each individual.

Statistical differences among control and treatment periods were determined by using ANOVA for repeated measures. Post-hoc comparisons were made by Scheffe $F$-test on Macintosh computer (Statview SE+Graphics, Brainpower, Inc. Calabasas, CA, USA) 


\section{Acknowledgements}

We are grateful to Mr Richard and Mrs Marilyn Wallen (Hubbard Lake, MI, USA) for providing high quality sheep for this study; Mr Douglas D. Doop and Ms Juanita Pelt and Shepard S. Kosut for expert technical advice and assistance; Dr Gordon D. Niswender, Colourado State University, and Dr Leo E. Reichert, Jr, Albany Medical College for providing reagents used in the LH assay. Important contributions were made by members of various Core Facilities of the Center for the Study of Reproduction (NIH P30 HD 18258): Gary R. McCalla of the Sheep Research Core Facility for conscientious animal care; the staff of the Assays and Reagents Core Facility for standardization of hormone radioimmunoassay reagents; the staff of the Administrative Core Facility for administrative and computer assistance. Supported by grants from the NIH (HD-18394 and -18258).

\section{Accepted 8 May 1998}

\section{References}

1 Foster DL, Bucholtz DC. Glucose as a possible cue timing puberty. In: Bergada C, Moguilevsky JA eds. Serono International Symposium on Puberty: Basic and Clinical Aspects, Rome, Italy: Ares-Serono Symposia, 1995: 319-331.

2 Wade GN, Schneider JE, Li H-Y. Control of fertility by metabolic cues. Am J Physiol 1996; 270: E1-E19.

3 Tatman WR, Judkins MB, Dunn TG, Moss GE. Luteinizing hormone in nutrient-restricted ovariectomized ewes. J Anim Sci 1990; 68: 1097-1102.

4 Foster DL, Bucholtz DC, Herbosa CG. Metabolic signals and the timing of puberty in sheep. In: Plant TM, Lee PA eds. The Neurobiology of Puberty. Bristol: Journal of Endocrinology Ltd, 1995: 243-257.

5 Maeda K-I, Nagatani S, Estacio MA, Tsukamura H. Novel estrogen feedback sites associated with stress-induced suppression of luteinizing hormone secretion in female rats. Cell Mol Neurobiol 1996; 16: 311-324.

6 Williams NI, Lancas MJ, Cameron JL. Stimulation of luteinizing hormone secretion by food intake: evidence against a role for insulin. Endocrinology 1996; 137: 2565-2571.

7 Schreihofer DA, Renda F, Cameron JL. Feeding-induced stimulation of luteinizing hormone secretion in male rhesus monkeys is not dependent on a rise in blood glucose concentration. Endocrinology 1996; 137: 3770-3776.

8 Clarke IJ, Horton RJE, Doughton BW. Investigation of the mechanism by which insulin-induced hypoglycemia decreases luteinizing hormone secretion in ovariectomized ewes. Endocrinology 1990; 127: 1470-1476.

9 Goubillon M-L, Thalabard J-C. Insulin-induced hypoglycemia decreases luteinizing hormone secretion in the castrated male rat: involvement of opiate peptides. Neuroendocrinology 1996; 64: 49-56.

10 Chen M-D, Ordog T, O'Byrne KT, Goldsmith JR, Connaughton MA, Knobil E. The insulin hypoglycemia-induced inhibition of gonadotropinreleasing hormone pulse generator activity in the rhesus monkey: roles of vasopressin and corticotropin-releasing factor. Endocrinology 1996; 137: 2012-2021

11 Bucholtz DC, Vidwans NM, Herbosa CG, Schillo KK, Foster DL. Metabolic interfaces between growth and reproduction. V. Pulsatile LH secretion is dependent upon glucose availability. Endocrinology 1996; 137: 601-607.

12 Nagatani S, Bucholtz D, Murahashi K, Estacio M, Tsukamura H, Foster D, Maeda K. Reduction of glucose availability suppresses pulsatile luteinizing hormone release in female and male rats. Endocrinology 1996; 137: $1166-1170$

13 Murahashi K, Bucholtz DC, Nagatani S, Tsukahara S, Tsukamura H, Foster DL, Maeda K-I. Suppression of LH pulses by restriction of glucose availability is mediated by sensors in the brain stem. Endocrinology 1996; 137: 1171-1176.

14 Howland B. Effect of glucoprivation induced by 2-deoxy-d-glucose on serum gonadotropin levels, pituitary response to GnRH and progesterone-induced release of luteinizing hormone in rats. Hormone Metabolism Res 1980; 12: 520-523.

15 Mangels RA, Jetton AE, Powers JB, Wade GN. Food deprivation and the facilitatory effects of estrogen in female hamsters: the LH surge and locomotor activity. Physiol Behav 1996; 60: 837-843.

16 Foster DL, Olster DH. Effect of restricted nutrition on puberty in the lamb: patterns of tonic luteinizing hormone ( $\mathrm{LH})$ secretion and competency of the LH surge system. Endocrinology 1985; 116: 375-381.

17 Goodman RL. Neuroendocrine control of the ovine estrous cycle. In: Knobil E, Neill JD eds. The Physiology of Reproduction. New York: Raven Press, 1994: 659-709.

18 Freeman ME. The neuroendocrine control of the ovarian cycle of the rat. In: Knobil E, Neill JD eds. The Physiology of Reproduction. New York: Ravan Press, 1994: 613-658.

19 Evans NP, Dahl GE, Mauger DT, Padmanabhan V, Thrun LA, Karsch FJ. Does estradiol induce the preovulatory gonadotropin-releasing hormone $(\mathrm{GnRH})$ surge in the ewe by inducing a progressive change in the mode of operation of the GnRH neurosecretory system. Endocrinology 1995; 136: 5511-5519.

20 Thompson CI, Fleming RL, Franken KA, Hornback DA, Boha SP. Dual 24-hour feeding response to $2 \mathrm{DG}$ in rats: daytime increase and nighttime decrease. Physiol Behav 1989; 45: 155-161.

21 Challet E, Le-Maho Y, Pevet P, Nobelis P, Malan A. Ventromedial hypothalamic lesions prevent the fasting-induced changes in day-night pattern of locomotor activity. Behav Brain Res 1996; 77: 155-163.

22 Jackson GL, Thurmon JC, Nelson D. Estrogen-induced release of LH in the ovariectomized ewe: Independence of time of day. Biol Reprod 1975; 13: 358-362.

23 Jackson GL, Thurmon J. Absence of a critical period in estrogen-induced release of LH in the anestrous ewe. Endocrinology 1974; 94: 918-920.

24 Ryan KD, Foster DL. Neuroendocrine mechanisms involved in onset of puberty in the female: concepts derived from the lamb. Fed Proc 1980; 39: $2372-2377$.

25 Moenter SM, Caraty A, Locatelli A, Karsch FJ. Pattern of gonadotropinreleasing hormone $(\mathrm{GnRH})$ secretion leading up to ovulation in the ewe: existence of a preovulatory GnRH surge. Endocrinology 1991; 129: $1175-1182$.

26 Martin GB, Thomas GB, Terqui M, Warner P. Pulsatile LH secretion during the preovulatory surge in the ewe: Experimental observations and theoretical considerations. Reprod Nutr Dev 1987; 27: 1023-1040.

27 Tanaka T, Mori Y, Hoshino K. Hypothalamic GnRH pulse generator activity during the estradiol-induced LH surge in ovariectomized goats. Neuroendocrinology 1992; 56: 641-645.

28 Kesner JS, Wilson RC, Kaufman JM, Hotchkiss J, Chen Y, Yamamoto H, Pardo RR, Knobil E. Unexpected responses of the hypothalamic gonadotropin-releasing hormone 'pulse generator' to physiological estradiol inputs in the absence of the ovary. Proc Natl Acad Sci USA 1987; 84: 8745-8749.

29 Nishihara M, Sano A, Kimura F. Cessation of the electrical activity of gonadotropin-releasing hormone pulse generator during the steroidinduced surge of luteinizing hormone in the rat. Neuroendocrinology 1994; 59: 513-519.

30 Adam CL, Findlay PA, Moore AH. Acute Effects of Insulin on LH Secretion in Sheep. Society for the Study of Fertility, Nottingham, Abstract Series, No. 17. Cambridge: Journals of Reproduction and Fertility Ltd. 1996; 43-44.

31 Karam JH, Forsham PH. Pancreatic hormones and diabetes mellitus. In: Greenspan FS, Baxter JD eds. Basic and Clinical Endocrinology. Norwalk, CT: Appleton and Lange, 1994: 571-634.

32 Schneider JE, Wade GN. Availability of metabolic fuels controls estrous cyclicity of Syrian hamsters. Science 1989; 244: 1326-1328.

33 Karsch FJ, Bowen JM, Caraty A, Evans NP, Moenter SM. Gonadotropin-releasing hormone requirements for ovulation. Biol Reprod 1997; 56: 303-309.

34 Goodman RL. The site of the positive feedback action of estradiol in the rat. Endocrinology 1978; 102: 151-159.

35 Caraty A, Fabre-Nys C, Delaleu B, Locatelli A, Bruneau G, Karsch FJ, Herbison A. Evidence that the mediobasal hypothalamus is the primary site of action of estradiol in inducing the preovulatory gonadotropin releasing hormone surge in the ewe. Endocrinology 1989; 139: 1752-1760.

36 Battaglia DF, Krasa HB, Viguie C, Karsch FJ. Immune stress disrupts the estrogen-induced LH surge: interference with estrogen signal processing or surge generation? Biol Repro 56, 93.

37 Suda T, Tozawa F, Yamada M, Ushiyama T, Tomori N, Sumitamo T, Nakagami Y, Denuma H, Shizume K. Insulin-induced hypoglycemia increases corticotropin-releasing factor messenger ribonucleic acid levels in rat hypothalamus. Endocrinology 1988; 123: 1371-1375.

38 Chen M-D, O’Byrne KT, Chiappini SE, Hotchkiss J, Knobil E. Hypoglycemic 'stress' and gonadotropin-releasing hormone pulse 
792 Glucose availability and luteinizing hormone surge generator activity in the rhesus monkey: Role of the ovary. Neuroendocrinology 1992; 56: 666-673.

39 Engler D, Pham T, Fullerton MJ, Ooi G, Funder JW, Clarke IJ. Studies of the secretion of corticotropin-releasing factor and arginine vasopressin into the hypophysial-portal circulation of the conscious sheep: I. Effect of an audiovisual stimulus and insulin-induced hypoglycemia. Neuroendocrinology 1989; 49: 367-381.

40 Caraty A, Grino M, Locatelli A, Guillaume V, Boudouresque F, ConteDevolx B, Oliver C. Insulin-induced hypoglycemia stimulates corticotropin-releasing factor and arginine vasopressin secretion into hypophysial portal blood of conscious, unrestrained rams. J Clin Invest 1990; 85: 1716-1721.

41 Daley CA, Sakurai H, Adams TE. Cortisol blocks or delays the preovulatory surge of LH in sheep. Biol Repro 1997; 56(Suppl.): 170.

42 Moberg GP, Watson JG, Stoebel DP, Cook R. Effect of cortisol and dexamethasone on the oestrogen-induced release of luteinizing hormone in the anoestrous ewe. J Endocrinol 1981; 90: 221-225.

43 Walsh JP, Clarke IJ. Effects of central administration of highly selective opioid mu-, delta- and kappa-receptor agonists on plasma luteinizing hormone $(\mathrm{LH})$, prolactin, and the estrogen-induced LH surge in ovariectomized ewes. Endocrinology 1996; 137: 3640-3648.

44 Foster DL, Ryan KD. Endocrine mechanisms governing transition into adulthood: a marked decrease in inhibitory feedback action of estradiol on tonic secretion of luteinizing hormone in the lamb during puberty. Endocrinology 1979; 105: 896-904
45 Claypool LE, Foster DL. Sexual differentiation of the mechanism controlling pulsatile secretion of luteinizing hormone contributes to sexual differences in the timing of puberty in sheep. Endocrinology 1990; 126: $1206-1215$.

46 Foster DL. Preovulatory gonadotropin surge system of prepubertal female sheep is exquisitely sensitive to the stimulatory feedback action of estradiol. Endocrinology 1984; 115: 1186-1189.

47 Karsch FJ, Dierschke DJ, Weick RF, Yamaji T, Hotchkis J, Knobil E. Positive and negative feedback control by estrogen of luteinizing hormone secretion in the rhesus monkey. Endocrinology 1973; 92: 799-804.

48 Hauger RL, Karsch FJ, Foster DL. A new concept for control of the estrous cycle of the ewe based upon temporal relationships between luteinizing hormone, estradiol, and progesterone inhibits tonic LH secretion. Endocrinology 1977; 101: 807-817.

49 Ebling FJP, Wood RI, Karsch FJ, Vannerson LA, Suttie JM, Bucholtz DC, Schall RE, Foster DL. Metabolic interfaces between growth and reproduction III. Central mechanisms controlling pulsatile luteinizing hormone secretion in the nutritionally growth-limited female lamb. Endocrinology 1990; 126: 2719-2727.

50 Niswender GD Jr, Reichert LE Jr, Midgley AR, Nalbandov AV. Radioimmunoassay for bovine and ovine luteinizing hormone. Endocrinology 1969; 84: 1166-1173.

51 Legan SJ, I'Anson H, Fitzgerald BP, Fitzovich D. Does the seasonal increase in estradiol negative feedback prevent luteinizing hormone surges in anestrous ewes by suppressing hypothalamic gonadotropin-releasing hormone pulse frequency? Biol Reprod 1985; 33: 117-131. 